The labour-pains commenced on the previous Saturday morning, early. In the course of that day the membranes ruptured. The precise period of that event I endeavoured to learn, but could not ascertain. The pains continued active until Monday, when they began to flag. Ergot of rye was then given, and we must snppose, from the character of the case, very improperly; but no increase of parturient action was induced by its exhibition. It was then determined to operate by cephalotomy, which was attempted to be accomplished by the barbarous instruments to which $I$ have alluded.

The air of the room smelled most offensively, the discharges being putrid. I found, on my arrival, that the parties in professional attendance had gone home to refresh themselves. I retired to another room until their return. On their arrival, in a few minutes after, I proceeded to examine into the state of the case. The cranial bones I found overlapping one another; the cerebral substance had been discharged; there were spiculæe and edges of bone projecting against the vaginal mucous membrane in all directions; the genital surfaces, as far as could be inspected, were of the colour of very dark mahogany, and devoid of all sensibility. I removed the cranial bones, excepting the base of the skull, previously diminishing their size and removing the sharp projecting spiculy by the osteotomist, and thus simplifying the case as much as possible. Now that I could apply traction without the least risk of tearing the vaginal walling, I fixed the guarded crotchets upon the base of the skull, and thus, without difficulty, effected the delivery of the head, the face being directed to the pubes. A considerable quantity of offensive gas was now expelled at intervals from the uterus. I next attempted, by traction applied to the base of the skull, the delivery of the shoulders, but failed of my object, which $I$ attributed to the chest and abdomen being filled with putrid gas. I brought down the mast accessible arm, which I could only do by the use of the blunt hook, the pelvic cavity being so completely oecupied by the inflated trunk. The perforator was guided by the arm to the axilla, at which point I now opened the chest, and evacuated the gas from that cavity and from that of the abdomen. Room was thus afforded by the collapsing trunk for the application of the body-guarded crotchet (traction by the base of the skull not, even now, sufficing), the size of the chest being further diminished by the compressing force exerted with that instrument. The delivery, which occupied half an hour, was then readily completed. A profuse discharge of a brown fluid, of most foetid odour, now escaped, and in larger quantity on the application of a bandage around the abdomen. The placenta, in a very putrid state, was removed without difficulty. The vagina and uterus were well syringed of their very putrid contents, with warm water and solution of chloride of soda. The uterus showed scarcely any disposition to contract; there was no hæmorrhage; indeed, there was not activity of circulation sufficient to sustain an hæmorrhage. When I left, the pulse was intermitting, the skin clammy, the breathing very laborious, and there was a muttering delirium. Being urged to the delivery of a prognosis, I prognosticated, as the least informed might have done ander the circumstances, that the patient could not possibly live many hours. The patient died at half-past four on the following morning.

Remarks. - No one who has paid common attention to the history of this case can come to any other conclusion than that the life of the sufferer, the subject of it, was completely sacrificed to ignorance, pretension, and an utter want of the common feelings of humanity, on the part of the consulted practitioner. Many of the readers of this Journal will probably conclude that the so-called "6onsulting surgeon-accoucheur" was no surgeon at all, but a sheer quack. I am sorry, however, to add, that by diploma he was; but I can further state, as a saving clause, having since been informed of his former history by one of his teachers, that this man, who had the cool assurance to style himself a " consulting surgeonaccoucheur," had been the most idle and irregular member of his midwifery class. His death took place, fortunately, we may say, for patients who were likely to become the subject of his obstetric operations, about three years ago.

What should have been, and what would have been, the treatment of the patient in question under the care of a well-informed obstetric attendant? She had previously been in sound good health, of firm fibre and active habits, and had never had a day's illness. She was in labour now, for the first time, at the age of forty, and in all probability would most judiciously have been treated by the timely abstraction of blood to eighteen, twenty, or twenty-five ounces; such, at least, corresponds with our experience under similar circumstances. There is no doubt, from the sequel of the case, that at some former period of its history, some hours subsequently to the escape of the liquor amnii, probably on the Sunday, there had been much febrile action in the system, and considerable phlogosis of the parts more immediately concerned in the business of the labour, which should have furnished an indication for the adoption of the above measure.

Had that treatment been had recourse to, and in sufficient time to be of service, it is possible that a further exertion of the natural efforts would have accomplished delivery. The employment of the forceps, however, might, on account of the position of the head not being the most favourable, have become necessary; but then, after venesection to an adequate amount, and the head had descended lower into the cavity of the pelvis, their application would have been comparatively safe and easy in dexterous hands, and the delivery of a living child might, possibly, have thus been secured, and danger to the mother arrested. There was no absolute deficiency of the pelvic space, and the child was of the average size. The difficulty had depended upon malposition of the child's head. How, was it that, when the delivery was attempted on the Monday, when she must already have been much exhausted by her struggles, and the uterus in particular so much so, that it could not be roused to further exertions by the ergot of rye, it was not completed within an hour, or any other reasonable period of time? The answer is too apparent.

In conclusion, I fervently hope that the much-to-beregretted case, recorded in the foregoing narrative, and which, with its horrible particulars, I never can forget, may answer some useful purpose, as a warning to those, and few, I trust, they are, who may feel disposed to attach the same light weight to the importance of midwifery studies as did the culpable party in whose hands it occurred.

Russell-place, Fitzroy-square, June 24, 1844.

\section{THE LOCAL PATHOLOGY OF NEURALGIA.}

By Ebenezer Skae, M.D., Edinburgh.

Having observed, in The LANCET of Saturday, the 27th of July last, an extract from " Dr. Ranking, in the "Provincial Journal," on the Local Pathology of neuralgia, in which this subject is explained by Dr. Black upon anatomical principles, I take leave to state that the view which is there given was suggested four years ago in a paper on Tic Douloureux, communicated by me, and contained in the "Edinburgh Medical and Surgical Journal" for July, 1840. The explanation of Dr. Black proceeds on the principle that the affected nerves, being "contained in rigid canals, must be subjected to injurious pressure whenever their accompanying vessels are unusually distended with blood." And, again, according to Dr. Wallis, "upon this pressure depends the nelcalgic paroxysm."

To what extent this view of the pathology of neuralgia was anticipated by myself may be inferred from a perusal of the following brief extract from my above-mentioned paper on Tic Douloureux, which, I may here observe, was founded on a case of facial neuralgia, a necroseopic examination of which indicated that the symptoms had proceeded from thickening of the dura mater in that portion of the base of the cranium throngh which are transmitted the maxillary branches of the trigemini :"But in assuming that the exciting cause of facial neuralgia may, in some cases, be local, and that such an ex- 
citing cause may be compression of the nervous trunk, I would not be understood as insinuating that, in all cases of this description, there must be more or less thickening of the 'dura mater' around the cranial exit of the affected nerves, but merely that, as in this case, the symptoms of tic were produced by compression of the trigemini, so, in like manner, pressure from any other cause might give rise to the same symptoms. On this principle it does not seem unreasonable to suppose that facial neuralgia may be produced by disturbance of the circulating fluids in the vessels adjacent to the nervous trunks, especially by an increased rolume of blood in a situation where the rigidity of the neighbouring structures prevents a ready diffusion of the pressure; or the same effects will be obviously produced by determination of blood to the vascular membranous envelop of the nerves themselves, particularly where they pass through osseous canals. That these local causes may sometimes contribute to the production of tic seems the more probable from the fact of dyspeptic affections being a common source of determination of blood to the brain and its appendages." It is highly probable that such an opinion of the local pathology of neuralgia may have occurred to Drs. Black and Wallis as an original conception of their own, and they may thus have been led to give it publicity as one altogether new, at the same time it is but right that it should be known that this view of the disease, whatever value may be attached to it, has already been submitted to the attention of the profession.

Leven, Fifeshire, August 5, 1844.

\section{ON THE \\ COMPARATIVE VALUE OF CHEMICAL AND PATHOLOGICAL DATA \\ IN \\ DISEASES OF THE KIDNEYS.}

To the Editor of THe LANCET.

SIR, - I observe in the last LANCET an exposition of Mr. Ross's views on albuminuria, and as whatever falls from the pen of that gentleman is deserving the consideration of the profession, I am desirous of directing attention to a few weak points, as they appear to me, in the paper alluded to. There is an absence, in the first place, of all local pathology, which is a necessary foundation for the establishment of doctrines of the highest importance to medicine; there is very little notice taken of the lesions of the kidney, and particularly of conditions, necessary and accidental, attendant on Bright's disease. Mr. Ross has also entirely overlooked, and does not seem to be aware of the experiments of Robinson and Bowman, who have satisfactorily shown that albuminuria is a consequence of congestion of the kidneys produced by compression of its vessels.

These experiments have been more influential to a right understanding of the conditions of abnormal urine than any other researches of modern date, after the researches of Dr. Bright. I do not wish to withhold from Mr. Ross the credit that is due to him for the introduction of new modes of pathological research, but I wish it to be remembered that the old modes are perhaps as good, and better, than the new, and that they must notbedisregarded in conducting pathological inquiries.

Are we not, Sir, too precipitate in applying chemical doctrines to the study of disease before these doctrines have been thoroughly established? Error can scarcely be avoided, for we know that the science of chemistry is constantly undergoing important changes. Even different teachers at the present moment hold very opposite views on many points of physiology. There can be no doubt that the science of chemistry is a highly important means of diagnosis in disease, but it should be very warily applied, and I expect that even Mr. Ross, with all his tajent and research, will soon find it necessary to pursue his way cautiously through the labyrinth of chemical investigation.

Before I close these brief remarks I will just allude to the doctrine of nutrition, as taught by Mr. Ross, in contradistinction to the views published by Liebig and others.
The former gentleman believes that non-nitrogenised food is really and truly nitrogenised in the system; the latter, that no such process takes place. Here is a great sea of separation between them at the very out set of our physiological researches. I do not mean to inquire who has the best of the argument, but simply to suggest it as an additional reason why your readers should receive the chemical doctrines of disease with caution, let them come any authority they may. I am, Sir, your most obedient humble servant,

Westminster, July 8, 1814.

\section{F OREIGR DEPARTMENT.}

\section{ACADÉMIE DE MÉdECINE, PARIS.-JULY.}

\section{DEBATE ON THE PRESENT DIRECTION OF OPHTHAL-} MALOGY.

The discussion on this subject has been less varied and interesting than was anticipated, principally owing to M. Gerdy's having made an interminable speech, which occupied all the leisure of the academy during three sittings, and so exhausted the patience of its members that, after allowing $M$. Velpeau to reply, they closed the debate. We will briefly analyse the speeches of M. Gerdy, and of $M$. Velpeau, his principal antagonist, which may be said to embrace the entire proceedings.

M. GERDY commenced by stating that in describing ophthalmiæ, as in describing all other diseases, we must begin by a general account of all the affections of the same kind, and then pass on to their modifications. These modifications ought sooner to be designated modes than species, as, in the sciences, species are established on more important and general distinctions. The distinguishing characters of ophthalmia must be drawn successively from all the characters which furnish notable differences to pathology, viz., the causes, the anatomical characters, the symptoms, the progress and termination, of the disease. All these data are important, and although they are not equally so, there is no reason why we should merely consider some and neglect the others. If, however, in opposition to reason, we persist in attempting to distinguish ophthalmixe by one character alone, that character ought sooner to be sought for in the evident nature of the ophthalmia than in the nature of the tissue which is the seat of disease. The fact of the inflammation being situated in this or that tissue, is a character which does not constitute the essence of the disease; it is evidently a relative character, to a certain extent foreign to the disease, the existence of which is so independent of the diversity of texture that it may appear in all the tissues of the eye. If we were to adopt the ophthalmalogical doctrines which are now gaining ground in France, and which are, in certain respects, more erroneous than those of the German school; if we were to assume, with M. Berard, that ophthalmix are only to be distinguished by the nature of the tissue attacked, what would be the consequences which would follow? We should be obliged either to suppress the distinctions founded on the causes, the symptoms, the progress of the disease, and, consequently, to cease to recognise any distinctions between scrofulous, rheumatic, and syphilitic ophthalmia, or even between slight and intense, acute and chronic, ophthalmia; or, otherwise, we should be obliged to make these forms of disease subordinate to the distinctions of tissue; thus admitting scrofulous, rheumatic, syphilitic conjunctivitis, keratitis, iritis, \&c. Were this the case, in order to distinguish in books species and varieties which do not exist in nature, the various symptoms would be arbitrarily divided among the pseudo-forms of disease established in pathological tables This is already the case with nearly all oph thalmiæ, with purulent conjunctivitis, with keratitis, and especially with the internal and deep-seated inflammations of the eye although the isolation of the latter cannot be appreciated either by ocular examination or by the symptoms. The inflamed tissues are too deeply seated for it to be possible to examine them, and the symptoms are necessarily 